\title{
The perils of omission
}

\author{
Paul Malik MD FRCPC
}

$\mathrm{A}$ variety of self-reported official documentation asks applicants to personally certify the validity of reported information. Everything from employment applications to tax returns ask for the information that is self-professed to be given in good faith. Likewise, testimony given in court is preceded by an oath to the truth. I have yet to hear a medical history conducted in this manner, which is a laughable idea because it seems intuitive for patients to reveal the truth, lest some harm befall them from the sin of omission. As many seasoned clinicians will attest, however, lies and omitted truths are part of daily practice. In this way, the clinician must play the role of a judge. That is, to judge the quality of information, not the behaviour. Unlike in the legal system, however, the clinician cannot confront and penalize once a lie is discovered. Such a tactic would only serve to alienate the patient. Instead, the deceit must be addressed in an open, nonjudgemental manner. Although it sounds paternalistic, patients must at times be protected from themselves. Deceit must be distinguished from a history obtained from a nonarticulate individual - the so-called 'vague historian'. The difference lies in conscious intent - a distinction that can, at times, be difficult.

There are certain components of the medical history that physicians are taught to scrutinize for accuracy. These include self-reporting of medication adherence, substance abuse and sexual activity. Reasons for patient deception are many and varied. They include everything from wishing to please the physician and embarrassment to avoiding a lecture. Yet, almost any component of the history is vulnerable to inaccuracies, which may have dire consequences. Consider the following cases.

In Newfoundland, Lynia Ross had chest pain in her third trimester of pregnancy. Her father and brother had both died of aortic rupture from Marfan's syndrome at the ages of 34 and 29 years, respectively. She had seen Dr Jeffrey Hiscock, an internal medicine specialist, in August 1996. When asked about family medical history, Ross did not disclose her family's history of Marfan's syndrome. Ross was treated for viral pericarditis, and her pain resolved. However, within a week, her pain returned more intensely. She finally told hospital staff about her family history. Unfortunately, surgical intervention was unsuccessful, and she died. Ross's baby was delivered by cesarean section, but died a week later due to maternal illness at the time of birth. The family sued Dr Hiscock for negligence from an inaccurate medical history. At the trial, it emerged that Ross lacked the typical physical findings of Marfan's syndrome, and that she had previously been told that she could

\section{Selected sites}

1. Medicine Net

$<$ www.medicinenet.com/script/main/

art.asp?articlekey $=46985>$

2. The Medical Post

$<$ www.medicalpost.com/opinions/columns/

article.jsp?content $=20060616 \_144319 \_5352>$ live a normal lifespan if the syndrome had been discovered and treated. She was knowledgeable about Marfan's syndrome and was urged to undergo an echocardiogram, but she declined. Her aunt's testimony revealed that she was "quite disturbed" by the deaths of her father and brother, and "didn't want to talk too much about it". She had also previously withheld her family history from other medical professionals. Ultimately, it was her fear and denial that caused her undoing. The judge sided with Dr Hiscock and stated that "a patient owes a duty to herself to do everything reasonably necessary to ensure she is properly diagnosed by her physician. As part of that duty, the patient must disclose all relevant and pertinent information in order to permit the physician to make a proper diagnosis of her medical condition...the doctor and patient relationship is a two-way street."

In another case, a mother in Ontario was convicted of hiding her HIV status while pregnant. Her physicians were denied the chance to treat the mother, and the child tested positive for HIV. The mother had tested positive for HIV when she immigrated to Canada and had been counselled on the means to prevent transmission during her first pregnancy. She followed her physician's advice during her first pregnancy, and the child had ultimately tested negative. Her second pregnancy was a different matter. The patient had discontinued antiretroviral therapy on her own. She delivered the child in a different hospital from where she had received prenatal care. She did not disclose her HIV status to hospital staff, and although bloodwork had been ordered at the second hospital, the results were not available at the time of delivery. The mother's status was discovered three days after the child was born. Although antiretrovirals were immediately administered, they were ineffective. The reasons for the mother's behaviour are unclear.

How can such tragedies to be prevented? Because deception may be part of any human interaction, how can we minimize the impact on the health of the patient? This is particularly important when a child is made to suffer the consequences. The cases illustrate the need for physicians to put patients at ease if they are to reveal their most private details. They also illustrate the need for a universal health record. Indeed, the information necessary to prevent these tragedies was known to the health care system, but it was not available to the right people at the right time. In addition to enabling cost savings by minimizing duplication of tests, a universal health record is the common thread in an era when multiple practitioners treat the same patient. For all that modern technology has to offer, it is built on the foundation of the medical history. If the history is inaccurate, everything collapses like a house of cards. 